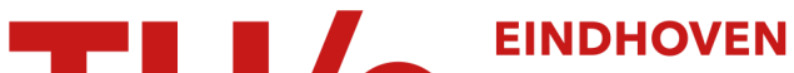

\section{Experiments with a large-scale reverse flow reactor}

\section{Citation for published version (APA):}

Nijdam, J. L., \& Geld, van der, C. W. M. (1997). Experiments with a large-scale reverse flow reactor. Chemical Engineering Science, 52(16), 2729-2741. https://doi.org/10.1016/S0009-2509\%2897\%2900094-8, https://doi.org/10.1016/S0009-2509(97)00094-8

\section{DOI:}

10.1016/S0009-2509\%2897\%2900094-8

10.1016/S0009-2509(97)00094-8

Document status and date:

Published: 01/01/1997

\section{Document Version:}

Publisher's PDF, also known as Version of Record (includes final page, issue and volume numbers)

\section{Please check the document version of this publication:}

- A submitted manuscript is the version of the article upon submission and before peer-review. There can be important differences between the submitted version and the official published version of record. People interested in the research are advised to contact the author for the final version of the publication, or visit the $\mathrm{DOI}$ to the publisher's website.

- The final author version and the galley proof are versions of the publication after peer review.

- The final published version features the final layout of the paper including the volume, issue and page numbers.

Link to publication

\section{General rights}

Copyright and moral rights for the publications made accessible in the public portal are retained by the authors and/or other copyright owners and it is a condition of accessing publications that users recognise and abide by the legal requirements associated with these rights.

- Users may download and print one copy of any publication from the public portal for the purpose of private study or research.

- You may not further distribute the material or use it for any profit-making activity or commercial gain

- You may freely distribute the URL identifying the publication in the public portal.

If the publication is distributed under the terms of Article 25fa of the Dutch Copyright Act, indicated by the "Taverne" license above, please follow below link for the End User Agreement:

www.tue.nl/taverne

Take down policy

If you believe that this document breaches copyright please contact us at:

openaccess@tue.nl

providing details and we will investigate your claim. 


\title{
Experiments with a large-scale reverse flow reactor
}

\author{
J. L. Nijdam and C. W. M. van der Geld* \\ Faculty of Mechanical Engineering, Eindhoven University of Technology, P.O. Box 513, \\ $5600 \mathrm{MB}$ Eindhoven, The Netherlands
}

(Received 23 May 1995; in revised form 2 July 1996; accepted 12 February 1997)

\begin{abstract}
Experiments have been performed in a full-scale ( $1.6 \mathrm{~m}$ diameter and $2.85 \mathrm{~m}$ height) cylindrical reverse flow reactor filled with torus saddles and operated with low thermal losses yielding a homogeneous temperature in the center. For gas mass flow rates up to $2.2 \mathrm{~kg} / \mathrm{s}$, the convective heat transfer is found to be dominant and the resulting temperature profiles are discussed for a number of conditions. The experimental results are compared with predictions of one-dimensional models. The agreement found is generally good. 1997 Elsevier Science Ltd
\end{abstract}

Keywords: reverse flow reactor; packed bed; non-catalytic combustion; convective heat transfer; gas purification; torus saddles.

\section{INTRODUCTION}

Packed beds of randomly dumped ceramic particles are applied in a large variety of industrial processes and, in a reverse flow reactor, the bed is an intermediary for heat or mass transfer between two gas streams. The reactor used in this study is applied as an end-ofpipe measure for the reduction of air pollution by industrial emissions of volatile organic compounds (VOC). These applications cover a wide range of discharge flow rates $\left(5.000-100.000 \mathrm{~m}^{3} / \mathrm{h}\right)$ and VOC-concentrations $\left(0-10 \mathrm{~g} / \mathrm{m}^{3}\right)$. The decontamination or deodorization of the gas streams occurs in the packed bed at a high temperature of typically $1000^{\circ} \mathrm{C}$. The thermal behavior of the non-catalytic combustor can be compared with that of a reverse flow catalytic reactor as first introduced by Matros, see e.g. Matros and Noskov (1993). Catalytic reactors of the autothermal kind, see Nieken et al. (1994), have recently gained interest for their application in converter systems of the automotive branch (Kirchner and Eigenberger, 1996). Different models of the non-catalytic reverse flow reactor have been derived and evaluated by Nijdam and van der Geld (1997).

Typical temperature profiles in the packed bed are 'hat-shaped' with the maximum occurring half-way in the bed, see Fig. 1. In the heating zone the entering gas is heated by the bed. At a sufficiently high temperature $\left(700^{\circ} \mathrm{C}\right.$ for natural gas), the VOCs start to react to $\mathrm{CO}_{2}$ and $\mathrm{H}_{2} \mathrm{O}$. In the mid-bed zone, reaction heat release and heat transfer are almost absent while in

*Corresponding author. E-mail cwm@wfw.wtb.tue.nl the gas cooling zone the heat taken up by the gas in the heating zone, and the reaction enthalpy, are partly returned to the bed in the gas cooling zone, resulting in decreasing gas temperatures. The cleansed gas mixture leaves the bed at an average temperature that is typically $40-70^{\circ} \mathrm{C}$ above the inlet temperature, dependent on the so-called adiabatic temperature drop. This is the temperature rise of the gas if all chemical reaction heat would be fully converted into sensible heat. Because the flow alters direction continuously, profiles are symmetrical. It is important to have minimal radial heat losses, especially in the high-temperature mid-bed zone (Eigenberger and Nieken, 1988). If the reactor casing is made of e.g. $1.5 \mathrm{~mm}$ steel (with its large heat diffusivity and heat capacity), and the bed diameter is small $( \pm 15 \mathrm{~cm})$, too large heat losses occur in the bed center and temperatures are not homogeneous there (van de Beld and Westerterp, 1996). Just with compensatory heating, problems occur because of the large heat capacity of the heating equipment (Eigenberger and Nieken, 1988). The importance of radial variations in catalytic combustion was demonstrated by, e.g. Daszkowski and Eigenberger (1992).

Consequently, the cylindrical reverse flow reactor used in this study was designed to overcome radial heat losses. It had a diameter of $220 \mathrm{~cm}$, a height of $300 \mathrm{~cm}$, was filled with ceramic torus with an open shape, that were relatively large $(25$ or $38 \mathrm{~mm}$ ) and at the inside of the casing, $30 \mathrm{~cm}$ thick ceramic blocks insulated the bed particles from the surroundings. The thermal diffusivity of ceramic is two orders of magnitude less than that of steel. Note that the influence of the insulation layer on the thermal dynamics of the 


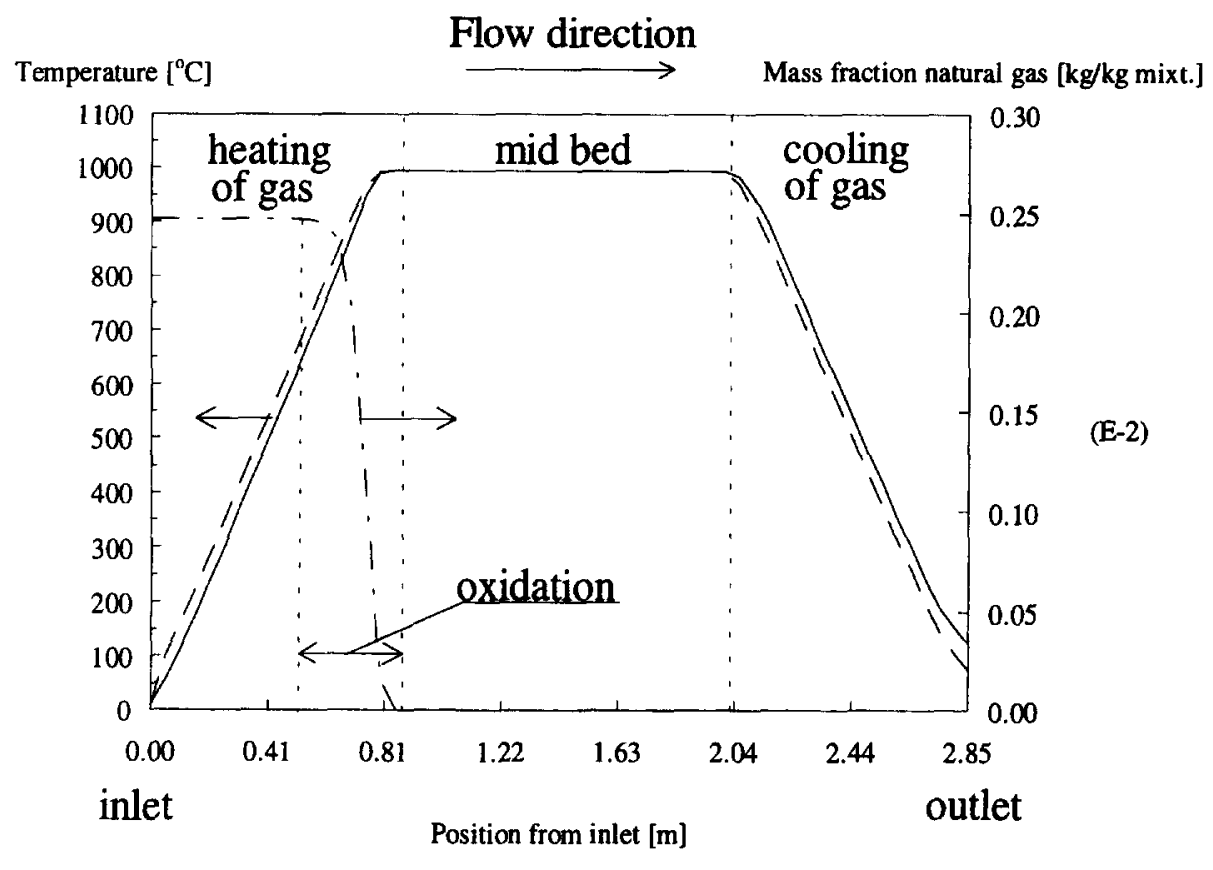

Gas

- Bed $\quad-\cdots$ Mass fraction

Fig. 1. Temperature and mass fraction profiles computed for a reverse flow reactor of saddles and a superficial air velocity of $0.42 \mathrm{~m} / \mathrm{s}$. Temperatures are plotted after $45 \mathrm{~s}$ of flow from the left of a mixture of air and $2.47 \mathrm{~g} / \mathrm{kg}$ natural gas.

whole system is mainly determined by this thermal diffusivity and is therefore negligible, especially since the cycle time is low, $90 \mathrm{~s}$, causing the temperature profiles in the bed to be almost stationary. Much longer cycle times have become customary to minimize the pollution due to the exhaust of remnants from the headers upon flow reversal. In the test rig of this study, a special feeding and exhausting procedure called 'puff-cleaning' is applied, as explained below. It solves this pollution problem and makes small cycle times possible. ${ }^{\dagger}$ Because of these measures and the large width of the bed the experimental results (nonisothermal) are suitable for testing the one-dimensional models developed in an earlier study (Nigdam and van der Geld, 1997). Each flow reversal causes a volume of contaminated gas which has not passed the mid-bed zone, the so-called puff, to be exhausted. This puff is mainly due to the volume of gas which had not reached the mid-bed zone as it is blown out at a flow reversal.

Prevention of the exhaust of contaminated gas is accomplished by directing the puff in a duct (length $25 \mathrm{~m}$, diameter $0.8 \mathrm{~m}$ ), an air buffer, where it is temporarily stored. This is achieved by shutting off the flow to the stack prior to a reversal by opening a valve to the air buffer and closing a valve to the stack, in this

'If long cycle times are used, the mid-bed temperatures are usually kept as low as possible to reduce thermal losses. If these thermal losses are low, only low concentrations of hydrocarbons $\left(2 \mathrm{~g} / \mathrm{m}^{3}\right)$ suffice to keep the reactor going. sequence. The valves remain in their position for another two seconds in order to direct all gas remainders that did not reach the bed center into the air buffer. Then the valve to the stacks opens again and the other one closes and cleaned gas flows to the stack. The puff in the air buffer is gradually added to the contaminated flow in the duct to the packed bed, at the suction side of the process fan. A pressure difference of $0.5 \mathrm{kPa}$ over the valve causes this addition.

As compared to the method discussed by Eigenberger (1992), the present puff-cleaning method has the advantage of low cost of investment. The former method requires three bed-halves to be installed, rather than the two in our method, and utilizes only two thirds of the available heat storage capacity at each instant of time.

The cleaning capacity of the puff-cleaning presented here amounts nearly $100 \%$ for natural gas (Nijdam, 1995). Components showing strong adsorption have a lower cleaning efficiency due to desorption.

Typical pressure drops across the entire generator (bed, ducts and valves) range in common practice from 2 to $4 \mathrm{kPa}$. Lower pressure drops could be realised by selecting a higher porosity for the bed. This would, however, decrease the volumetric surface area of the bed, reducing heat transfer efficiency. The shape of the bed particles and their size, determining the volumetric surface area, are chosen such that the total cost of energy (electricity for the process fan and natural gas for the preservation of bed temperatures) is minimum. Isothermal runs at ambient temperature 


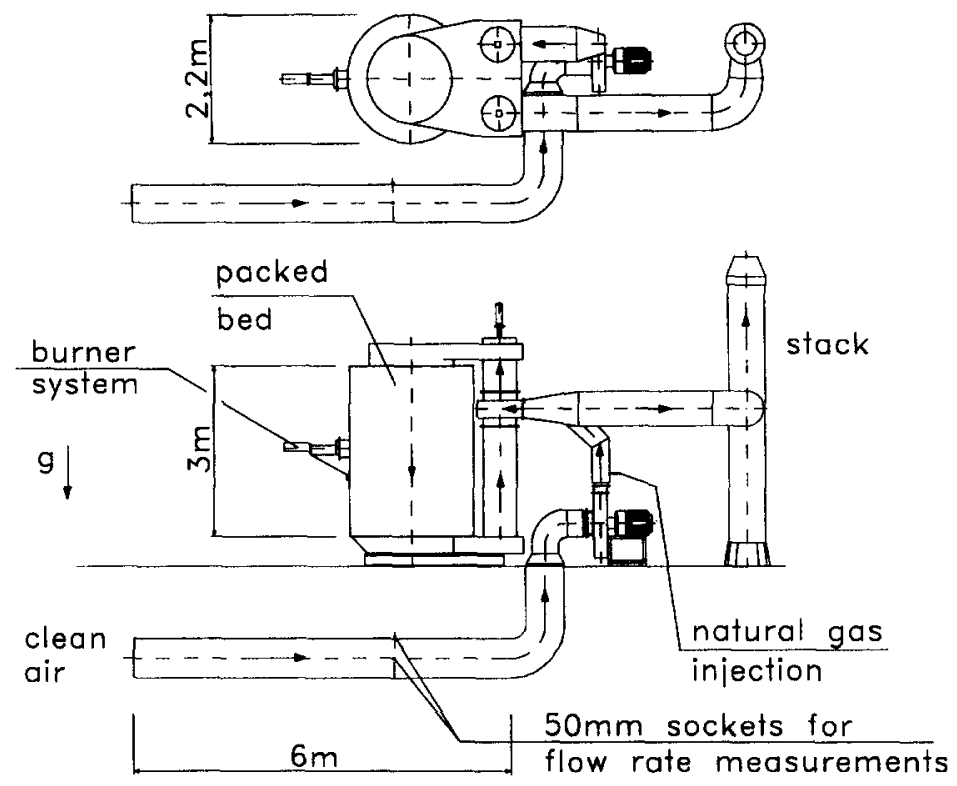

Fig. 2. Schematic of regenerator, process fan and air ducts.

have been performed for Reynolds numbers in the range from 800 onto 1900 and resulting pressure drops are compared with predictions using the correlations of Ergun and Kast (Brauer, 1971), and Mackowiak (1991).

\section{EXPERIMENTAL}

The test rig consists of a cylindrical reactor vessel, two especially designed two-way valves that alternately direct the air flow upwards or downwards through the bed, a process fan and control equipment (P.L.C. and frequency controller). Figure 2 presents a schematic of the test rig. During start-up of the regenerator, the bed is heated by a $70 \mathrm{~kW}$ burner, producing $1000^{\circ} \mathrm{C}$ flue gases that are distributed by perforated pipes in a horizontal plane halfway the packed bed. During the measurements, ambient air and organic compounds with a constitution to be described below are fed to the regenerator by means of a $45 \mathrm{~kW}$ process fan with its rotational speed controlled by a frequency controller. The air is transported to the regenerator through a straight pipe with diameter, $D$, of $0.6 \mathrm{~m}$ and length $6.3 \mathrm{~m}$. Air flow rates are measured in this duct at a distance $7 D$ downstream of the duct inlet, using a hot wire anemometer (Airflow Model TA5, accuracy $\pm 2 \%$ ). Velocity measurements are performed at six radial positions in the duct $(0.032 D ; 0.135 D ; 0.321 D ; 0.679 D ; 0.865 D$ and $0.968 D$ ), on a crossed horizontal and vertical line through the duct center. The radial positions are chosen such that the mean velocity is obtained directly from the average of the 12 measurements (Perry et al., 1984). It takes some time for the gas to reach the bed front after a flow reversal. This 'dead' time is denoted with $\tau_{\text {flush. }}$.

The vessel has a diameter of $2.2 \mathrm{~m}$ and a height of $3 \mathrm{~m}$, see Fig. 3. It is insulated at the inside by blocks of ceramic material $\left(40.6 \% \mathrm{Al}_{2} \mathrm{O}_{3}, 49.5 \% \mathrm{SiO}_{2}\right)$. The thickness of the insulation is $0.3 \mathrm{~m}$ and hence the bed diameter is $1.6 \mathrm{~m}$. During pouring, the saddles were frequently spread out and tamped in order to minimize future settling by weight, see appendix $\mathrm{A}$. The bed possesses four layers, ${ }^{\ddagger}$ see Fig. 3. The higher void fraction of the $38 \mathrm{~mm}$ saddles allows for homogeneous distribution of the flue gases from the burner during start-up.

Usually it takes 200 cycles $(5 \mathrm{~h})$ of operation to attain stable temperatures due to the low (order $0.001)$ thermal capacity ratio of gas and bed, $\varepsilon \rho_{g} c_{g} /$ $\left[(1-\varepsilon) \rho_{p} c_{p}\right]$. Measurements have been taken after weeks of continuous operation; new test conditions got $24 \mathrm{~h}$ to settle. During the measurements the temperature of the casing was constant. The same holds for the bed provided that measuring times were taken in phase with respect to the cycle variation.

Sixteen type K (NiCr-Ni) thermocouples (accuracy $\pm 2^{\circ} \mathrm{C}$ ) have been inserted in the bed. Their position is indicated as MP\# in the Fig. 3 (side view) and (4) (top view). The latter figure shows how each thermocouple is bent circumpherentially to prevent excessive forces due to thermal expansion of different materials and to minimize temperature gradients. Temperatures are measured with a digital thermometer with cold junction compensation (Eirelec model 5001) and a sixchannel temperature recorder (Kipp \& Zonen Model BD100, accuracy $\pm 1^{\circ} \mathrm{C}$ ). The temperature of the air at the inlet is measured using the built-in thermocouple of the anemometer (accuracy $\pm 1^{\circ} \mathrm{C}$ ). The

\$The bottom layer is for reinforcement and larger holes in the bottom plate. Computations show its presence to have hardly any effect on temperature profiles. 


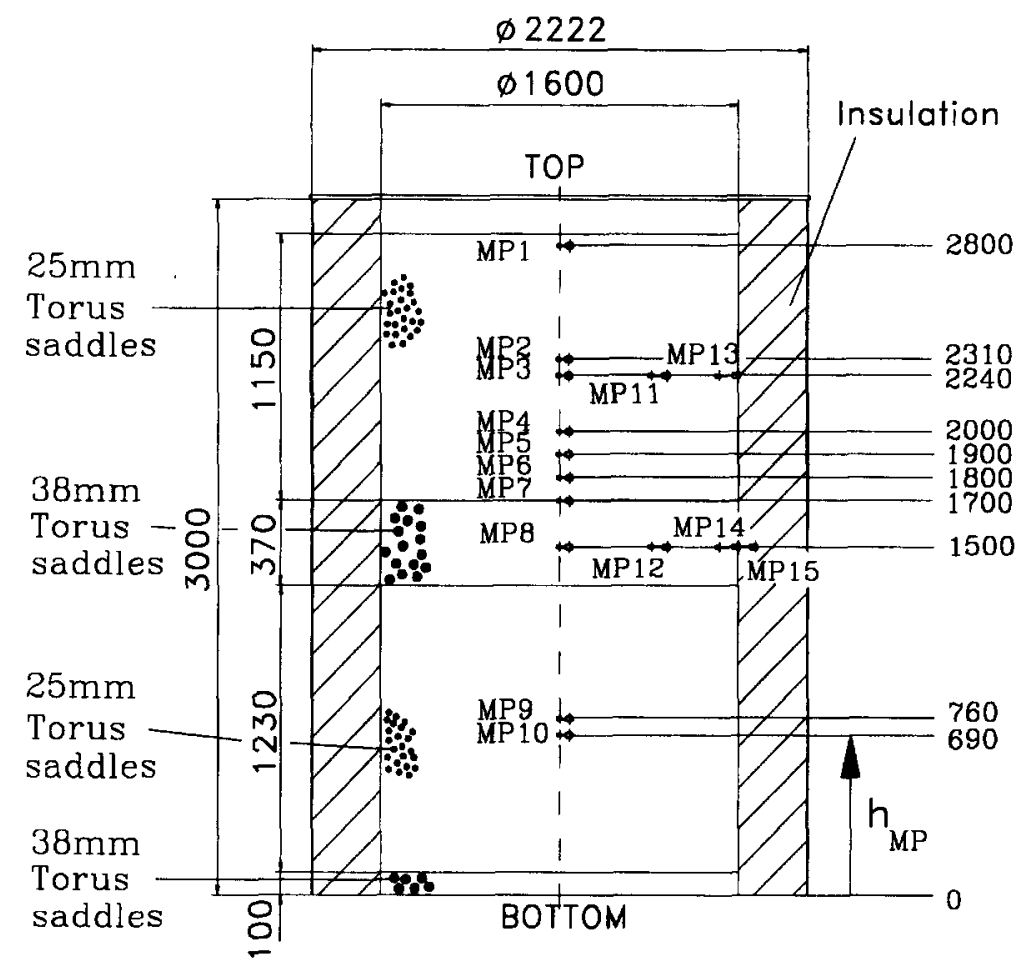

Fig. 3. Side view of thermocouple locations and composition of the packed bed. All dimensions in mm.

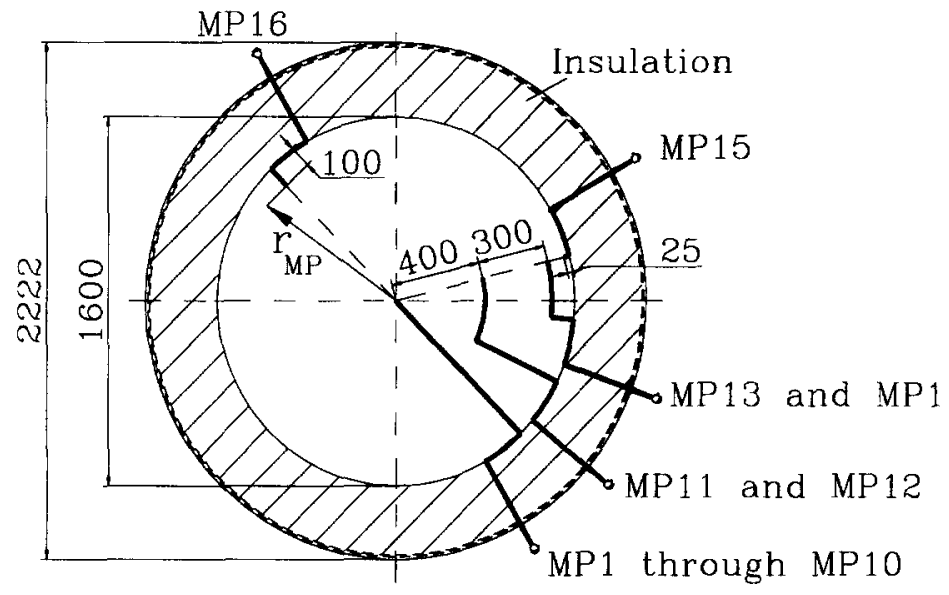

Fig. 4. Top view of thermocouple locations. All dimensions in mm.

air humidity at the inlet is measured by a wet bulb indicator (Sato Keiryoki, Wittich \& Visser, accuracy $\pm 5 \%$ ). Any lifting out of the horizontal plane of a thermocouple results in a positioning error of the thermocouple tip. The positioning accuracy of the tip corresponds to a rotation of $\pm 4^{\circ}$ out of the horizontal plane.

The temperature of the thermocouple stabilizes at a level which balances the heat fluxes to the probe from the gas (convection), the bed (conduction) and the ambient air (conduction). The major part of the surface is in contact with the flowing gas. The thermocouples therefore indicate a temperature inbetween that of the gas and that of the bed. At the moderate temperatures in the heating and cooling zones, radiation is negligible compared to heat transfer by forced convection (Flerzfeld, 1962). Van de Beld et al. (1994) with large cycle times (400-1600 s) measured differences between particle and gas temperatures of $20^{\circ} \mathrm{C}$ maximum. In the mid-bed zone the temperatures are typically $1000^{\circ} \mathrm{C}$, causing radiation to be important. In this section, however, gas, bed and thermocouple temperatures are virtually the same and steady state and transient errors are negligible. Steady state measuring errors due to conduction are ca. $3^{\circ} \mathrm{C}$ (Nijdam, 1995). Transient temperature variation is 
not responded to correctly by the thermocouple due to its thermal capacity, resulting in so-called transient errors. They are corrected, in a way described in appendix Appendix B.

In the duct between process fan and inlet valve, see Fig. 2, a small amount ( $2 \%$ typically) of natural gas is injected in the air flow through a multi-hole tube. The natural gas composition in \% volume is (Gasunie, 1988): methane 81.30 , nitrogen 14.35 , ethane 2.85 and others 1.5. The inlet mass fraction of natural gas, $x_{\mathrm{HC}}^{\text {in }}$, follows directly from the measured flow rates of natural gas and air. In addition, $x_{\mathrm{HC}}^{\mathrm{in}}$ is computed from the time-averaged difference of the specific enthalpy, $H$, of the gas mixture at outlet of the bed and that of the air at the inlet by

$$
\begin{aligned}
x_{\mathrm{HC}}^{\mathrm{in}}= & \frac{1}{\Delta H_{0}} \frac{1}{\tau} \int_{0}^{\tau}\left\{H\left(T^{\text {out }}(t), x_{\mathrm{H}_{2} \mathrm{O}}^{\text {out }}, x_{\mathrm{CO}_{2}}^{\text {out }}\right)\right. \\
& \left.-H\left(T^{\text {in }}, x_{\mathrm{H}_{2} \mathrm{O}}^{\mathrm{in}}, x_{\mathrm{CO}_{2}}^{\mathrm{in}}\right)\right\} \mathrm{d} t
\end{aligned}
$$

where $\Delta H_{0}$ denotes the lower combustion value of natural gas, $3.8 \times 10^{7} \mathrm{~J} / \mathrm{kg}$ (Gasunie, 1988), $\tau$ the flow cycle time (upwards and downwards), $T^{\text {out }}$ the timedependent temperature of the gas mixture at outlet of the test rig, $T^{\text {in }}$ the constant inlet temperature, $x_{\mathrm{H}_{2} \mathrm{O}}^{\text {out }}$ and $x_{\mathrm{CO}_{2}}^{\text {out }}$ the mass fractions of water vapor and carbon dioxide, respectively, at the outlet and $x_{\mathrm{H}_{2} \mathrm{O}}^{\text {in }}$ and $x_{\mathrm{CO}_{2}}^{\mathrm{in}}$ those at the inlet. The enthalpy correlation for dry air includes a contribution of $0.03 \mathrm{vol} \%$ $\mathrm{CO}_{2}$ in the air (Gasunie, 1988).

The heat losses to the ambient atmosphere have been measured with a heat flux sensor." It consists of a thermopile, a large number of thermocouples in series connection, embedded in a filling material. The diameter of the sensor is $25 \mathrm{~mm}$ and its thickness is $3 \mathrm{~mm}$. The sensor has been put on the steel wall at the outside of the test rig and has an accuracy of $\pm 5 \%$.

\section{RESULTS}

In each test run, mixtures of ambient air and natural gas are fed to the reactor at a constant flow rate, $\dot{m}_{g}$. Table 1 summarizes the main process conditions of the test runs. Errors indicated are computed according to Kline and McClintock (1953). The Reynolds number ranges from 300 (run 1, mid-bed zone) to 1600 (run 7, bed surfaces). Here $R e$ is based upon the interstitial gas velocity, $\dot{m}_{g} /\left(\varepsilon \cdot \rho_{g} \cdot A_{f r}\right)$, and the mean pore diameter, $d_{h}=6 \cdot V_{p} \cdot \varepsilon /\left\{A_{p} \cdot(1-\varepsilon)\right\}=$ $\varepsilon \cdot d_{\mathrm{eq}} /(1-\varepsilon)$, with $V_{p}$ and $A_{p}$ denoting the volume and

"Let the outlet temperature averaged over a cycle be denoted by $\left\langle T^{\text {out }}\right\rangle$. The heat capacity of the gas is approximately constant in the relatively small temperature range $\left[T^{\text {in }}, T^{\text {out }}\right]$. Equation (1) can therefore be written as

$$
x_{\mathrm{HC}}^{\text {in }}=\frac{1}{\Delta H_{0}}\left\{H\left(\left\langle T^{\text {out }}\right\rangle, x_{\mathrm{H}_{3} \mathrm{O}}^{\text {out }}, x_{\mathrm{CO}_{2}}^{\text {out }}\right)-H\left(T^{\text {in }}, x_{\mathrm{H}_{2} \mathrm{O}}^{\text {in }}, x_{\mathrm{CO}_{2}}^{\text {in }}\right)\right\} \text {. }
$$

'Developed by TNO Industrial Research. Institution of Applied Physics (TPD), P.O. Box 155, 2600 AD Delft. The Netherlands. surface area of a torus saddle, respectively. The cycle time, $\tau$, is selected constant and short $(90 \mathrm{~s})$ for reasons explained in Section 1, while the gas velocity is changed to investigate the effect of convective heat transfer.

\subsection{Temperatures}

Heat fluxes to the ambient air, $\dot{Q}_{\mathrm{amb}}$, have been measured on the outside of the insulation at different locations on the steel casing (see Table 2). The temperature drop due to losses, $\Delta T_{\text {loss }}=l_{\text {bed }} \cdot d_{\text {bed }} \cdot \pi \cdot \dot{Q}_{\text {amb }}$ $\left(\dot{m}_{g} \cdot c_{p}\right)$, ranges from 5 to $9^{\circ} \mathrm{C}$. Here $l_{\text {bed }}$ is the height of the bed $(3 \mathrm{~m})$ and $d_{\text {bed }}$ its outer diameter $(2.2 \mathrm{~m})$. The value of $\Delta T_{\mathrm{ad}}=\left\langle T^{\text {out }}\right\rangle-T^{\text {in }}+\Delta T_{\text {loss }}$ varies from 93 to 127 in the test runs. These values easily follow from the data in Tables 1 and 2 .

Typical temperature histories measured at MP2 (in the heating/cooling zone) for run 7 are presented in Fig. 5. This temperature increases and decreases approximately linearly in time, and this tendency is independent of the flow rate. Temperatures measured in the mid-bed zone are constant in time. The dotted line in Fig. 5 possesses the correct mean and maximum and minimum temperatures as found in the way described in Appendix B. The corrected temperature is more close to the gas temperature after $45 \mathrm{~s}$ of constant gas flow. Upon alternating the flow direction the temperature registered by the thermocouple is initially more close to the bed temperature. Then it rapidly comes close to the gas temperature. The ratio of the characteristic relaxation time of the thermocouple, $t_{t c}$, to the cycle time is too large in the example of Fig. 5 for the thermocouple to fully adapt the gas temperature. The thermal inertia of the $6 \mathrm{~mm}$ outer diameter thermocouples makes $t_{t \mathrm{c}}$ large, see Appendix $B$, causing the differences in measured and predicted temperatures in Fig. 5.

The difference between the maximum and minimum temperatures at a certain point in the bed equals twice the amplitude, $A_{T}$, defined in Fig. 5. The values for $A_{T}$ have to be corrected for transient errors as explained in Appendix B. The amplitudes are maximum at the top and at the bottom of the bed (MP1,2, 3,9 , and 10), as expected. The average temperatures, $T_{\mathrm{avg}}$, and the amplitudes $A_{T}$ of all test runs and all measuring points have been tabulated (Nijdam, 1995) and are available on request. The temperature profile histories of all tests can be reconstructed from these data.

Temperatures in the heating/cooling zone decrease with increasing mass flow rate. The gradient $\mathrm{d} T / \mathrm{d} z$ has the same tendency. This dependence on the mass flow rate is easily explained with the aid of correlations for $\mathrm{Nu}$ from the literature, see e.g. Matros (1985, 1989).

The gradients $\partial T / \partial z$ are found to be constant in each of the heating, mid-bed and cooling zones. The observed gradients being homogeneous implies that $\partial^{2} T / \partial z^{2}=0$. Axial diffusion apparently is negligible with respect to convective heat transfer and the latter therefore dominates. 
Table 1. Main process parameters of each test run.

\begin{tabular}{lccccccc}
\hline \multicolumn{1}{c}{ Run \# } & 1 & 2 & 3 & 4 & 5 & 6 & 7 \\
\hline$\dot{m}_{g}(\mathrm{~kg} / \mathrm{s})( \pm 0.05)$ & 1.069 & 1.103 & 1.337 & 1.454 & 1.667 & 2.033 & 2.204 \\
$T_{\text {in }}(\mathrm{C})( \pm 1)$ & 11.5 & 18.7 & 15.3 & 11.8 & 19.9 & 18.0 & 20.6 \\
$x_{\mathrm{H}_{2} \mathrm{O}}\left(\mathrm{g} \mathrm{H} \mathrm{H}_{2} \mathrm{O} / \mathrm{kg}\right.$ mixture $)( \pm 0.2)$ & 4.5 & 4.6 & 6.8 & 5.0 & 9.8 & 4.5 & 7.4 \\
$x_{\mathrm{HC}}(\mathrm{g}$ natural gas $/ \mathrm{kg}$ mixture $)( \pm 0.08)$ & 2.506 & 2.387 & 2.469 & 2.717 & 2.597 & 2.876 & 3.175 \\
$\tau(\mathrm{s})$ & 90 & 90 & 90 & 90 & 90 & 90 & 90 \\
$\tau_{\text {flush }}(\mathrm{s})( \pm 0.1)$ & 1.6 & 1.6 & 1.3 & 1.2 & 1.0 & 0.85 & 0.79 \\
\hline
\end{tabular}

Note: $x_{\mathrm{H}_{2} \mathrm{O}}^{\mathrm{in}}$ is the inlet gas humidity. The mass fraction of natural gas is denoted by $x_{\mathrm{HC}}, \tau_{\mathrm{flush}}$ is the 'dead' time after a flow reversal (see Section 3).

Table 2. Measurements of heat flux $\dot{Q}_{\mathrm{amb}}$ at the steel casing of the test rig

\begin{tabular}{lcc}
\hline$T_{\text {bed }}\left({ }^{\circ} \mathrm{C}\right)$ & Temperature ambient air $\left[{ }^{\circ} \mathrm{C}\right]$ & $\dot{Q}_{\text {amb }}\left(\mathrm{W} / \mathrm{m}^{2}\right)$ \\
\hline $310 \pm 2$ & $20 \pm 2$ & $295 \pm 15$ \\
$732 \pm 2$ & $22 \pm 2$ & $460 \pm 23$ \\
$950 \pm 2$ & $21 \pm 2$ & $557 \pm 28$ \\
\hline
\end{tabular}

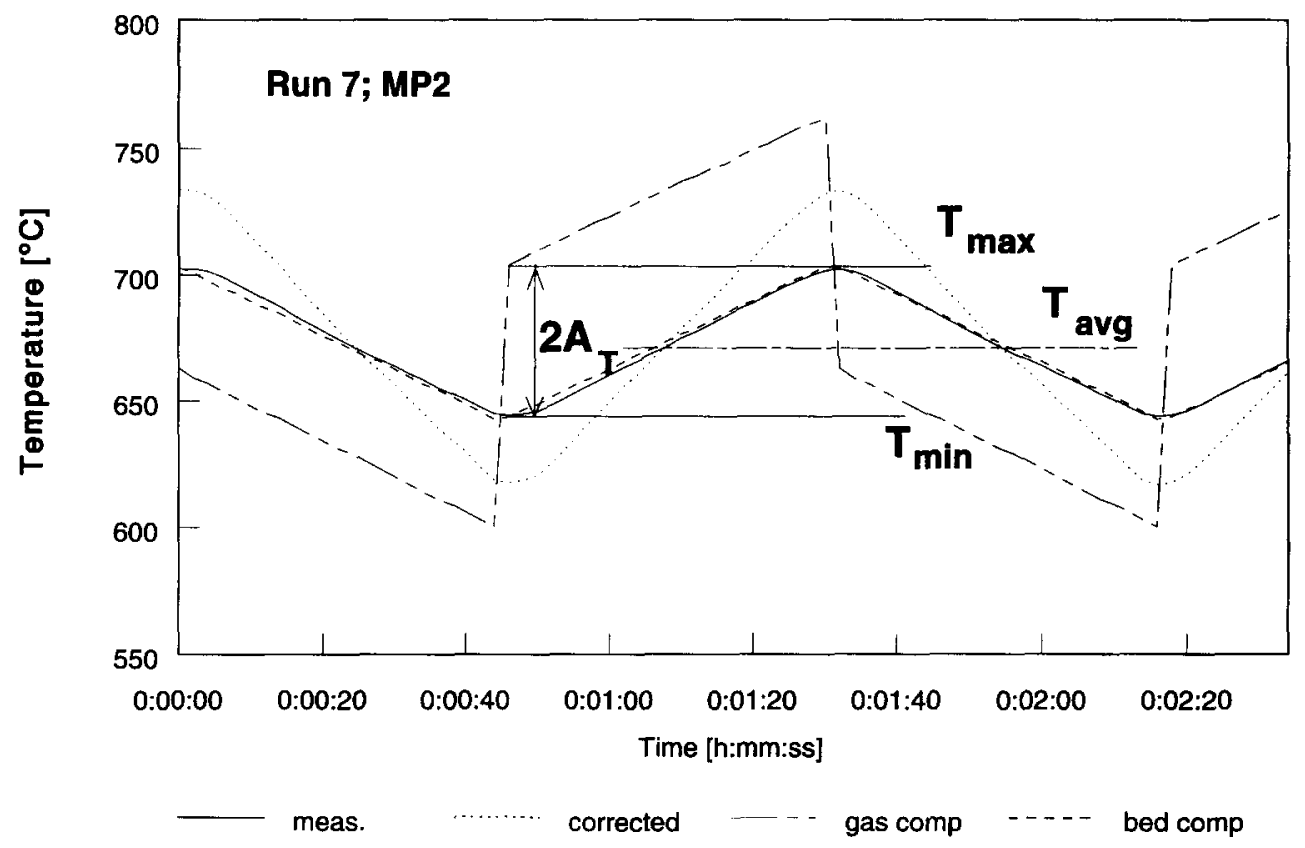

Fig. 5. Typical temperature histories measured and predicted in the heating/cooling zone.

Temperatures in the mid-bed zone, $T_{M B}$, are found to increase a little with increasing mass flow rate, see Fig. 6 and 7. Van de Beld et al. (1994) found the same tendency.

The radial temperature gradients in the mid-bed zone, where temperatures are highest, are negligible, see Fig. 7, thus the net heat flow from the bed to the surroundings is small. The heat losses to the ambient air are low, $500 \mathrm{~W} / \mathrm{m}^{2}$ (3.5 $\mathrm{kW}$ in total) typically, see Table 2, and those by axial conduction in the metal casing are estimated to be ca. $130 \mathrm{~W}$ only. Only at the borders of the mid-bed zone, the temperatures in the thermal insulation fluctuate due to the continuous shifting up and down of the bed temperature profile.
However, given the low cycle time, $90 \mathrm{~s}$, and the thick thermal insulation with a low thermal diffusivity the heat capacity of the insulation has a negligible effect on the bed temperature profiles and the heat losses.

\subsection{Pressure drop}

With the temperature profiles known, the variations of the gas mass density and viscosity can be computed. This is done by segmenting the bed into small slices with height $\Delta z$. In each slice the pressure drop is computed in three different ways as described in Nijdam (1995), see also Brauer (1971) and Mackowiak (1991). The total pressure drops, $\Delta P$, follow from a subsequent summation, and are compared 


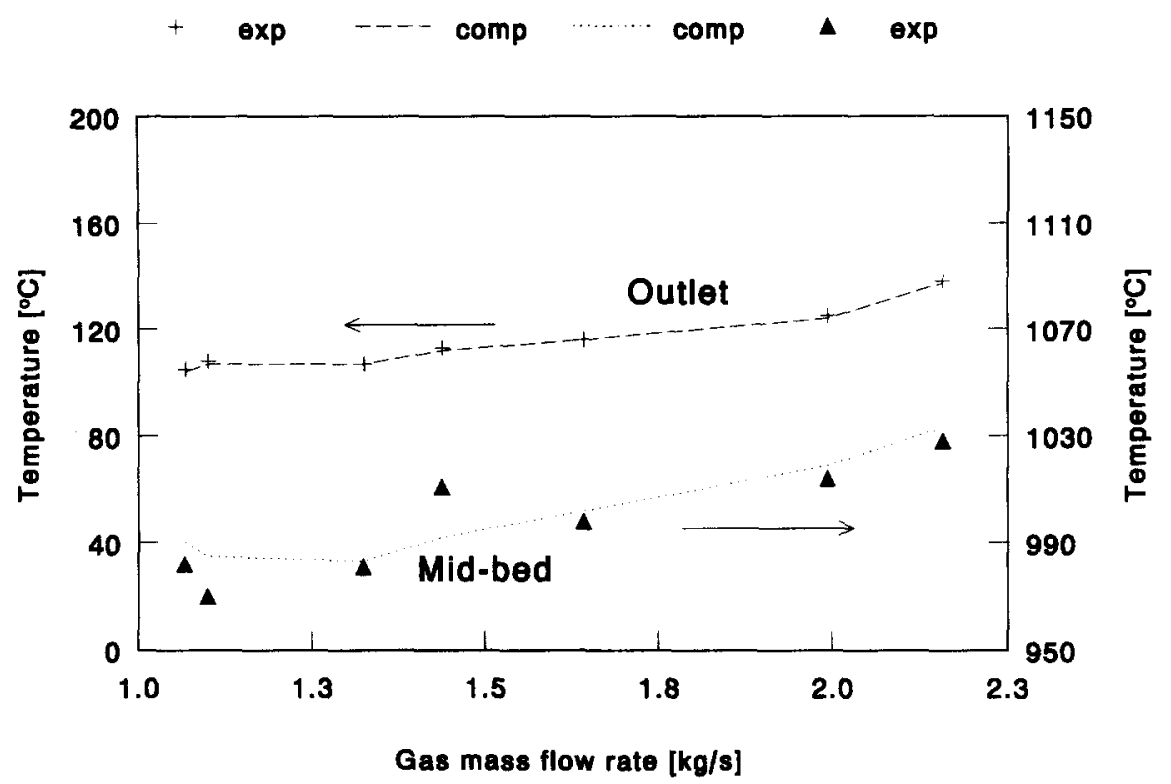

Fig. 6. Comparison of measured and predicted temperatures at the outlet and in the mid-bed zone.

\section{MP8, MP12, MP14 in mid bed zone}

Temperature $\Gamma^{\circ} \mathrm{Cl}$

Run 1

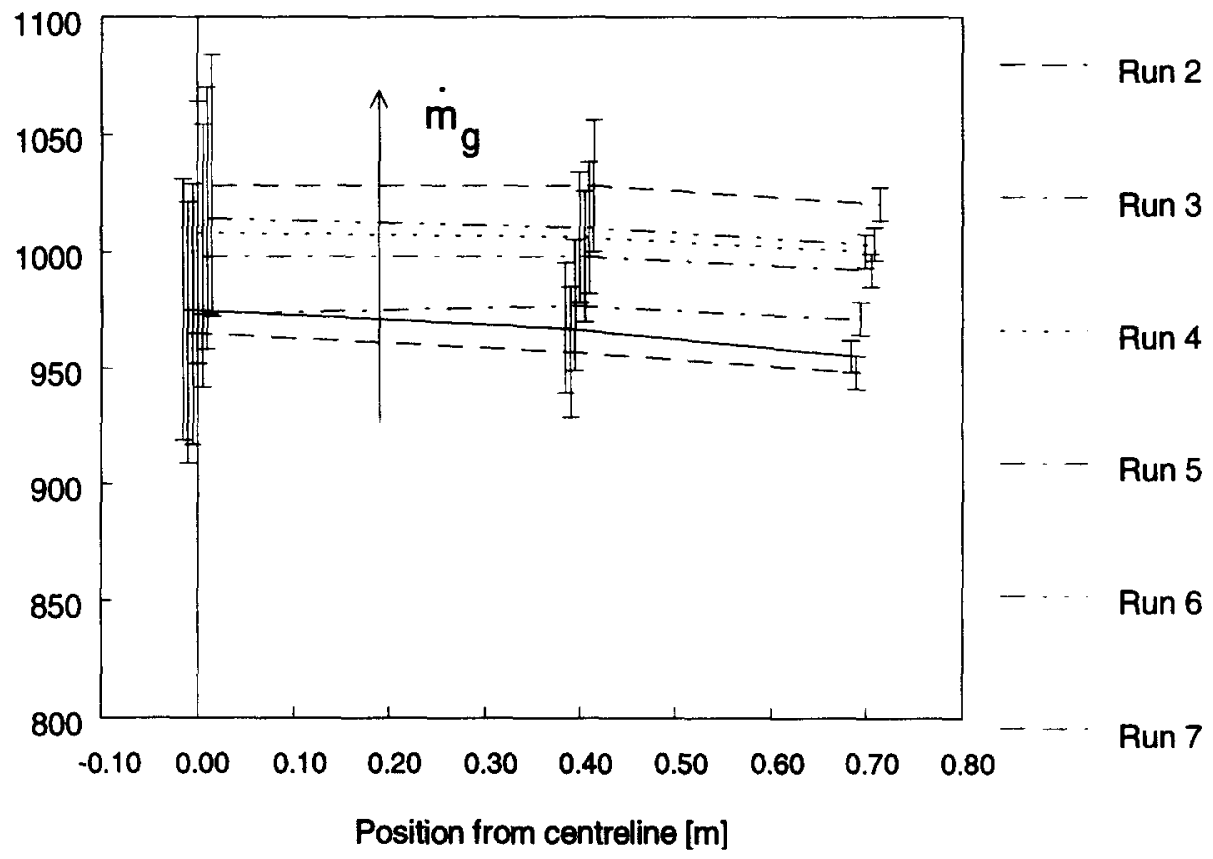

Fig 7. Temperature profiles in radial direction in the mid bed-zone.

with experiments in Fig. 8. The Reynolds number ranges from 300 (mid-bed zone, run 1) onto 1600 (bed surface, run 6).

Additionally, isothermal runs have been performed in which the entire bed is at a temperature of $15 \pm 1^{\circ} \mathrm{C}$. Ambient air at the same temperature is transported to the bed at seven different flow rates.
Experimental and computed pressure drops are presented in Fig. 9. The $R e-$ number ranges from 800 onto 1900.

The isothermal pressure drops predicted by the correlations of Ergun, Kast and Mackowiak differ by less than $15 \%$ from the experiments. This is acceptable, because of the expected prediction accuracy of 
+ Exp - Ergun Kast -........ Mackowiak

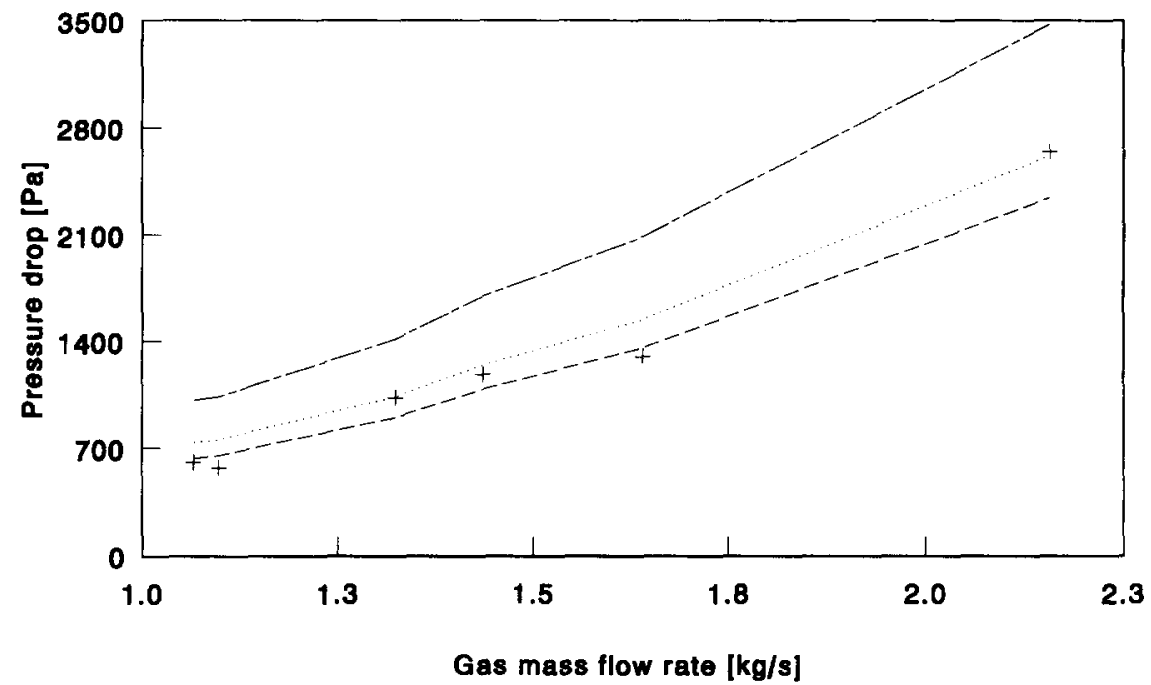

Fig. 8. Comparison of measured and predicted pressure drops for the heated bed; see Table 1 for operating conditions.

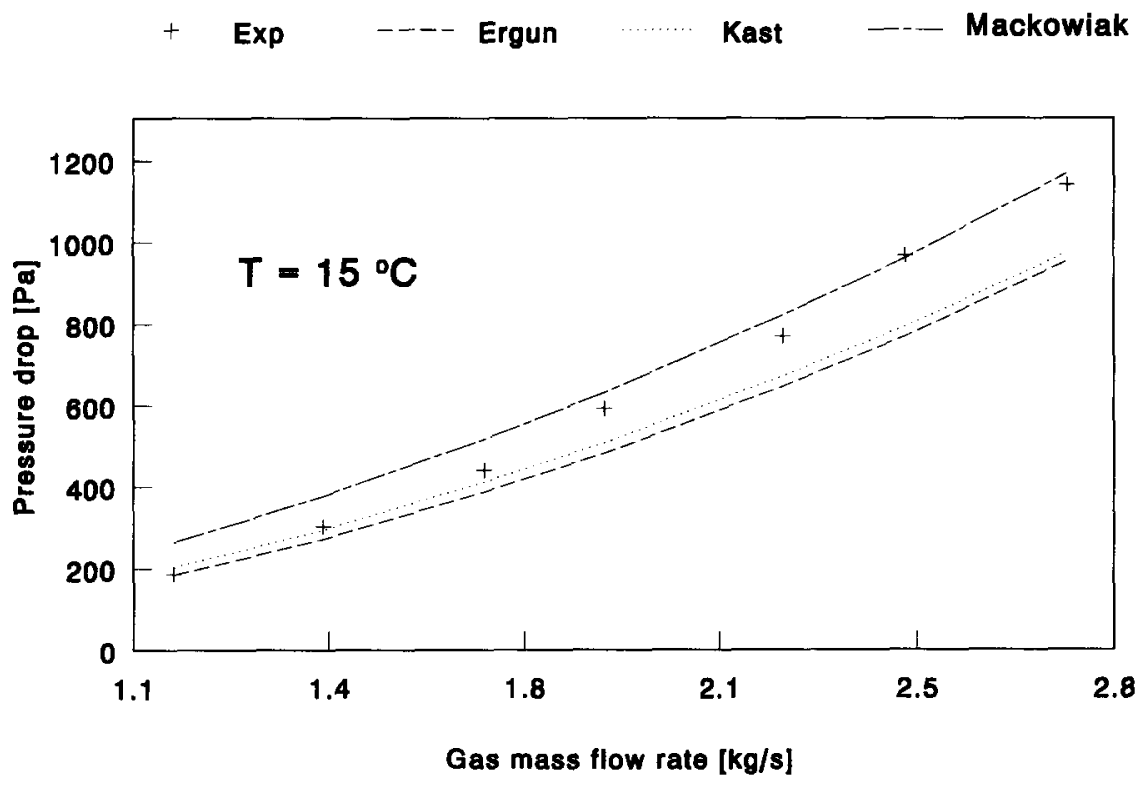

Fig. 9. Comparison of measured and predicted pressure drops for isothermal conditions.

ca. $20 \%$ due to the uncertainty in the void fraction. Only for the lowest flow rate, Mackowiak's correlation overpredicts the experimental value by $40 \%$.

The same accuracy of $15 \%$ is obtained for the heated bed with the correlations of Ergun and Kast. Mackowiak's correlation, however, overpredicts the pressure drop over the heated be by more than $50 \%$, particularly for the lowest flow rates of runs 1 and 2, see Fig. 8. For these conditions, a typical Reynolds number in the mid-bed zone is 300 , while the measurements used by Mackowiak (1991) ranged from 600 to 10,000 , probably causing the discrepancy found.
3.3. Shift velocities

Temperature fluctuations in the bed are the result of temperature gradients in flow direction, $\partial T / \partial z$, and the gradual shifting of the temperature profiles due to convection. This shifting happens at velocity $v_{s}$ that is defined as the speed at which a temperature disturbance propagates downstream. An expression for $v_{s}$ is easily derived for regions of the packed bed where no heat sources occur, see e.g. Levec and Carbonell (1985):

$$
v_{s}=\dot{m}_{g} \cdot c_{g} /\left\{(1-\varepsilon) \cdot \rho_{p} \cdot c_{p} \cdot A_{f r}\right\}
$$


Table 3. Measured axial temperature gradients, $\mathrm{d} T / \mathrm{d} z$

\begin{tabular}{cccccc}
\hline Run \# no. & 1 & 2 & 3 & 4 & 6 \\
\hline Measured ( $\left.{ }^{\circ} \mathrm{C} / \mathrm{m}\right)$ & $1059 \pm 170$ & $968 \pm 155$ & $902 \pm 145$ & $980 \pm 157$ & $925 \pm 148$ \\
\hline
\end{tabular}

Values of the ratio of $c_{g}$ and $c_{p}$ range from 1.2 at inlet of the bed to 0.8 in the mid-bed zone. The shift velocity is therefore roughly constant in the bed. Predictions with eq. (2) and $\varepsilon=0.68$ (see Appendix A) are gathered in Fig. 10.

Shift velocities are derived from measured temperatures in the following way. Almost by definition,

$$
v_{s}=-\frac{\mathrm{d} T_{p}}{\mathrm{~d} t} / \frac{\mathrm{d} T_{p}}{\mathrm{~d} z} .
$$

Since $\mathrm{d} T_{p} / \mathrm{d} z$ and $\mathrm{d} T_{g} / \mathrm{d} z$ are about the same, values for $\mathrm{d} T_{p} / \mathrm{d} z$ in the denominator of eq. (3) are obtained from measured gradients. Time-averaged axial temperature gradients $\partial T_{g} / \partial z$, in heating and cooling zones, have the same absolute value and are constant during flow in one direction. Measured temperature gradients are derived from the temperature difference of MP1 and MP3, divided by the distance $0.56 \mathrm{~m}$ between these two measuring points. In Table 3 measured gradients are presented.

An expression for the derivative $\mathrm{d} T_{p} / \mathrm{d} t$, is found by taking the time derivative of the governing equation for the bed temperature (Nijdam, 1988):

$$
\frac{\mathrm{d} T_{p}}{\mathrm{~d} t}=\frac{\mathrm{d} T_{g}}{\mathrm{~d} t}+\frac{\mathrm{d}}{\mathrm{d} t}\left(\frac{\dot{m}_{g} \cdot c_{g} \cdot \Delta z}{h \cdot A} \cdot \frac{\mathrm{d} T_{g}}{\mathrm{~d} z}\right) .
$$

Since $h$ is approximately constant (variation is less than $8 \%), c_{g}$ is the only variable in the RHS of eq. (4).
Substitution of $\mathrm{d} c_{g} / \mathrm{d} t$ by $\left(\mathrm{d} c_{g} / \mathrm{d} T\right) \cdot\left(\mathrm{d} T_{g} / \mathrm{d} z\right)$ results in

$$
\frac{\mathrm{d} T_{p}}{\mathrm{~d} t}=\frac{\mathrm{d} T_{g}}{\mathrm{~d} t} \cdot\left(1+\frac{\dot{m}_{g}}{h \cdot a_{\mathrm{bed}} \cdot A_{f r}} \cdot \frac{\mathrm{d} c_{g}}{\mathrm{~d} T} \cdot \frac{\mathrm{d} T_{g}}{\mathrm{~d} z}\right) .
$$

For the measuring conditions of all test runs, the second term between the brackets is of order 0.01 . The time rates of change of $T_{p}$ and $T_{g}$ are, therefore, approximately the same. Measured values of $\mathrm{d} T_{g} / \mathrm{d} t$ are computed from temperature histories like those of Fig. 5.

The experimental results with eq. (3) are compared with predictions in Fig. 10. In view of the measurement accuracies, see Section 2, and the approximations involved in eq. (2), the agreement is reasonably good.

\subsection{Temperature predictions}

Temperature distributions of gas and torus saddles are computed for each of the seven runs specified in Table 1 using a semi-analytical model. This one-dimensional model is applicable for reasons discussed in Section 3. Instantaneous values registered by the thermocouples are a weighed average of the gas and bed temperatures, see Section 2, which would make a comparison with instantaneous predictions cumbersome. Results for run 1 are presented in Fig. 11 and, except for the two thermocouples in the bottom part of the reactor a fair agreement is found between

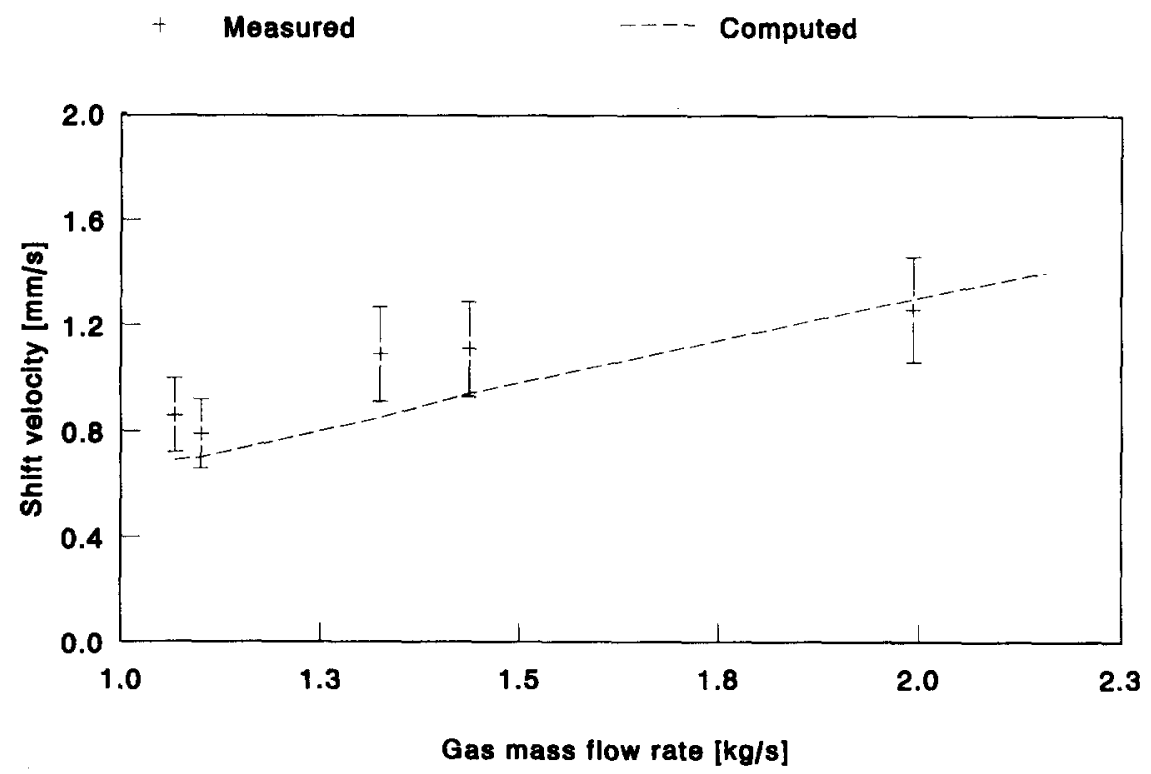

Fig. 10. Comparison of measured and predicted shift velocities; see Table 1 for operating conditions. 


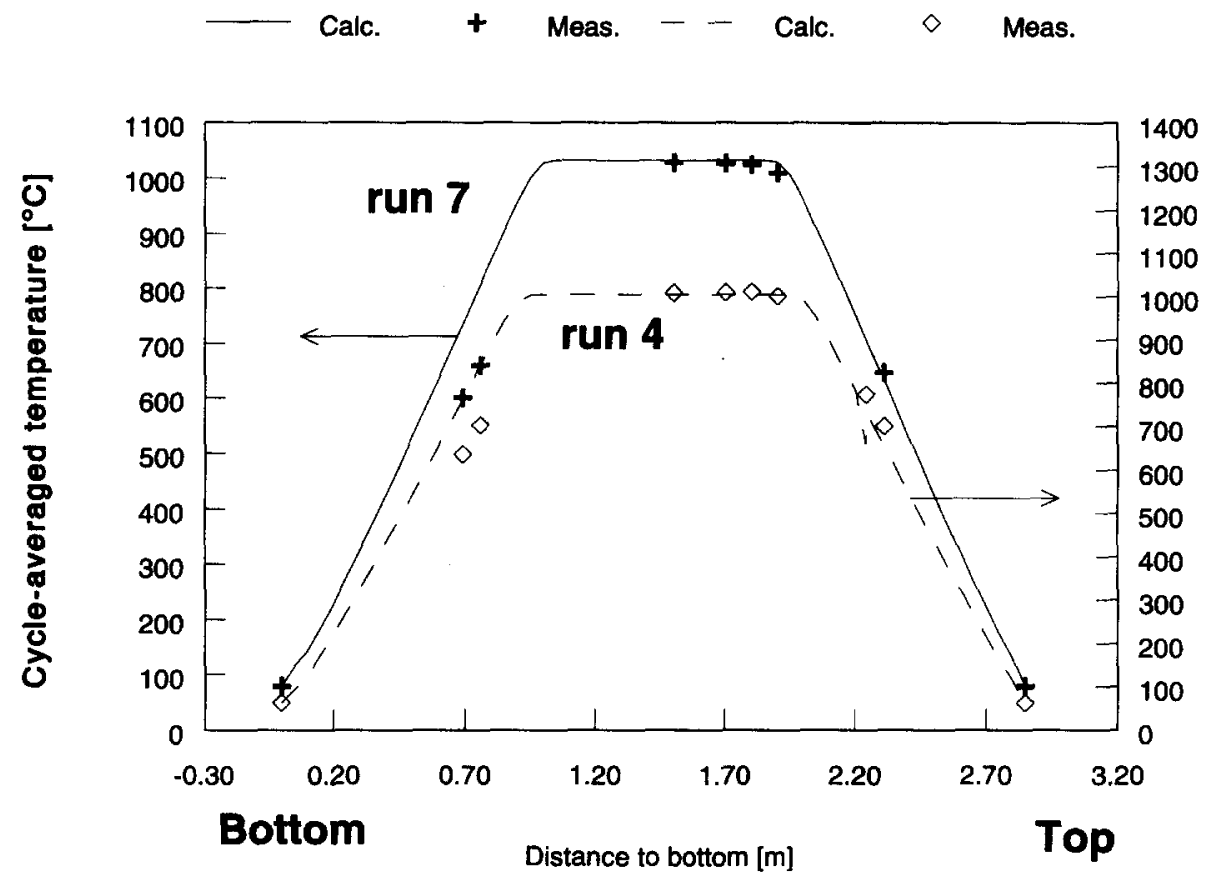

Fig. 11. Computed and measured cycle-averaged temperature profiles for runs 4 and 7 , see Table 1 for operating conditions. The cycle-averaged bed temperature profile is the same as that of the gas.

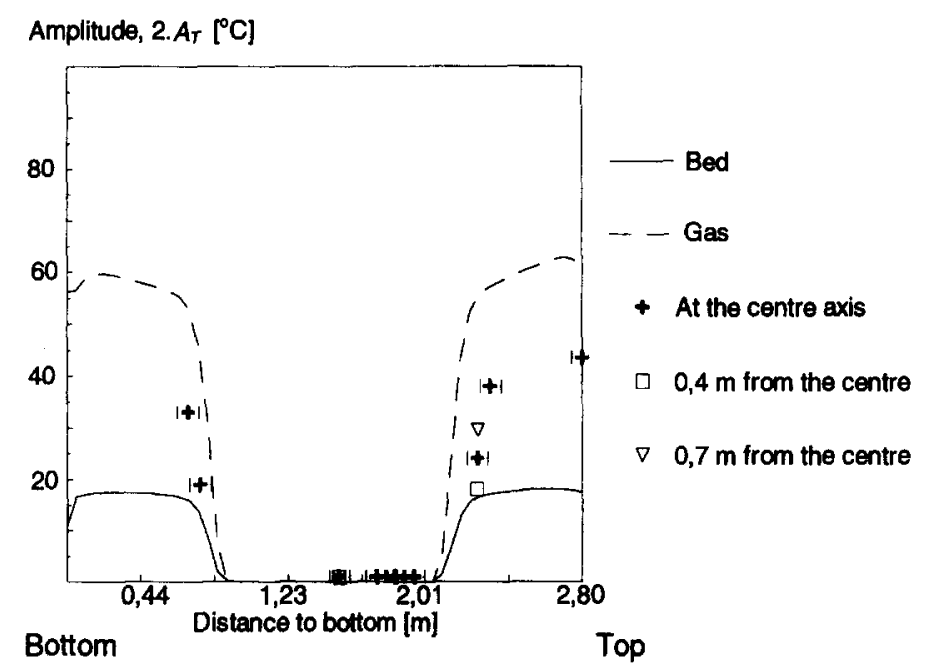

Fig. 12. Amplitude profiles of gas and solid phase for run 1, see Table 1 for operating conditions.

measured and computed temperatures. Similar results are obtained for the other measuring conditions of run $2-7$. Some comparison results are gathered in Fig. 6. For all test runs the agreement between measurement and prediction is fairly good.

Due to the shifting of the temperature profiles, temperatures in heating and cooling zone vary in time as shown in Fig. 5. This figure has been discussed in Section 3.1. Computed and measured amplitude distributions for run 1 are compared in Fig. 12. The measured amplitudes are approximately $40 \%$ less than the predicted gas amplitudes. This shows that the thermocouples register temperatures somewhat more close to the gas temperature at the end of a cycle as has been discussed in Section 3.1. The shape of the amplitude profiles for run 2 through run 7 is similar, with an approximately linear dependence of temperature amplitudes on the mass flow rate. This dependence is obvious from the constant cycle time and from expression (2) for the shift velocity.

The plateau temperature in principle depends on the ignition temperature of the component to be burnt, which depends on $E$, the Arrhenius term or frequency factor and the gas residence time. Note that reactions only occur in the part of the reactor upstream of the mid-bed zone. Despite of this, $T_{M B}$ alters 
by $15-20 \%$ if $E$ is varied by $\pm 10 \%$ while keeping the other parameters of the theoretical model constant.

\section{CONCLUSIONS}

Experiments are presented with a reverse flow reactor of torus saddles. The measured time-dependent temperature profiles in pseudo-stationary operation are fully characterized by the temperature of the midbed zone, $T_{M B}$, the gradients in the heating and cooling zone, $\partial T / \partial z$, the cycle time, $\tau$, and the amplitudes of temperature in the heating and cooling zone, $A_{T}$. The cycle time has been fixed at $90 \mathrm{~s}$. The values of $T_{M B}, \partial T / \partial z$, and $A_{T}$ have been tabulated and are available on request.

The observation that temperatures are constant throughout the entire mid-bed zone shows that radial heat losses are negligible. This was expected because of the design of the bed: its width, its thick internal insulation with low thermal diffusivity, combined with the small cycle time applied yielding low heat fluxes at the outside. For gas mass flow rates up to $2.2 \mathrm{~kg} / \mathrm{s}$, convective heat transfer is found to be dominant and axial diffusion to be negligibly small.

Pressure drops have been measured in the heated reactor (Reynolds numbers $R e$ varying from 300 to 1600 ) and at uniform ambient temperature (Reynolds numbers $800-1900$ ). Predictions by the correlations of Ergun and Kast (Brauer, 1971) deviate less than 15\%, but low-Reynolds number predictions by the correlation of Mackowiak (1991) can deviate by as much as $50 \%$.

The measured shift velocities show that eq. (2) predicts the shift velocity reasonably well.

A one-dimensional, semi-analytical MAT model (Nijdam, 1995; Nijdam and Van der Geld, 1997) has been used for simulations of the reverse flow reactor with torus saddles. The agreement of measurements and predictions is generally good.

\section{Acknowledgements}

The authors are grateful to Reox B. V. and Novem for financing this study.

\section{APPENDIX A. PACKING CHARACTERISTICS}

In this appendix, the bed materials used in the test rig are specified.

The mass density of the ceramic packing material, $\rho_{p}$, is according to the supplier $2400 \mathrm{~kg} / \mathrm{m}^{3}$. The heat capacity, $c_{p}$, and conductivity, $\lambda_{p}$, of the packing material have experimentally been determined by Carlowitz ${ }^{\dagger}$

$$
\begin{gathered}
c_{p}=\exp \left(6.59+5.31 \times 10^{-4} T\right) \quad(T \text { in } \mathrm{K}) \\
\lambda_{p}=0.8993+5.2113 \times 10^{-4} T-1.119 \times 10^{-7} T^{2}
\end{gathered}
$$

\footnotetext{
*Vereinigte Füllkörper Fabriken GmbH (VFF), RansbachBaumbach, Germany.

†Prof. Dr. Ing. O. Carlowitz. Fachhochschule Braunschweig/ Wolfenbüttel. Saldahlumer Strabe 46-48, 38302 Wolfenbüttel, Germany.
}

Some of the particle properties have experimentally been determined in our laboratory. A cylindrical vessel of $0.280 \mathrm{~m}$ diameter and $0.295 \mathrm{~m}$ height has been filled completely with $25 \mathrm{~mm}$ saddles and the number of saddles in the cylinder was counted. Subsequently water was added. The amount of water that could be poured into the cylinder until it runs over has been measured (accuracy \pm 0.11 ). The experiment was carried out twice: for a relatively open bed structure created by filling the cylinder gently and for a relatively dense bed that was tamped frequently during the filling. The number of saddles in the cylinder was $1350 \pm 20$ and $1500 \pm 20$ and volume water was $13.1 \pm 0.11$ and $12.4 \pm 0.11$, respectively. In addition, the mass of $100 \mathrm{dry}$ saddles has been measured: $0.92 \pm 0.01 \mathrm{~kg}$. Subsequent results for $\rho_{\text {bed }}, \varepsilon$ and the number of particles per unit bed volume, $N$, are presented in Table A1. The void fractions measured in this way are in fair agreement with values given by the supplier.

The volumetric surface area, $a_{\text {bed }}$, follows from the surface area of one saddle, $a_{1}$, as $a_{\mathrm{bed}}=N \cdot a_{1}$. The surface $a_{1}$ of a saddle with average dimensions has been computed using the AutoCad AME-module. Characteristic dimensions of the saddle are defined in Fig. Al. The characteristic lengths $H$. $W$ and S, see Fig. A1, are $36.1 \pm 0.6 \mathrm{~mm}, 20.4 \pm 0.5 \mathrm{~mm}$ and $3.4 \pm 0.2 \mathrm{~mm}$, respectively. The value computed for $a_{1}$ is $2468 \pm 60 \mathrm{~mm}^{2}$, leading to the volumetric surface areas given in Table Al.

\section{APPENDIX B. CORRECTION OF TEMPERATURE MEASUREMENTS FOR TRANSIENT ERRORS}

In transient situations, thermocouples lag behind any change in gas temperature due to their thermal capacity resulting in the so-called transient errors. In this appendix, a correction method for transient errors is presented. Transient errors, $E_{T}$, in heating and cooling zones are estimated from (Herzfeld, 1962)

$$
E_{T}=T-T_{t c}=t_{t c} \cdot \frac{\mathrm{d} T_{t c}}{\mathrm{~d} t}
$$

with $t_{t c}$ the so-called characteristic time, defined by

$$
t_{t c}=\rho_{t c} \cdot c_{t c} \cdot d_{t c} / h
$$

Here $\rho_{t c}$ is the mass density of the thermocouple, $c_{t c}$ its heat capacity, $d_{c c}$ its diameter and $h$ the convective heat transfer coefficient. The value of $t_{t c}$ of the probes with a $6 \mathrm{~mm}$ outside diameter tubing has experimentally been determined in quiescent air, resulting in a value $t_{t c}^{\text {exp }}$ of $230 \mathrm{~s}$. Values for $t_{t c}$ for the measurements in the packed bed are derived from $t_{t c}^{e^{x_{\mathrm{p}}}}$ by

$$
t_{\mathrm{tc}} \approx t_{\mathrm{tc}}^{\exp } \cdot \frac{h^{\exp }}{h}
$$

with the convective heat transfer coefficient for the calibration experiment with natural convection, $h_{\text {exp }}$, being $13 \mathrm{~W} /\left(\mathrm{m}^{2} \mathrm{~K}\right)$.

Temperature histories as that of Fig. 5 show that $T_{\mathrm{tc}}$ changes linearly with time between two flow reversals. The timederivative of $T_{t c}$ in the RHS of (B1) is therefore approximated by

$$
\left|\frac{\mathrm{d} T_{t c}}{\mathrm{~d} t}\right|=2 \cdot \frac{A_{T}}{\tau}
$$

with $A_{T}$ the measured amplitude and $\tau$ the cycle time of the regenerator $(90 \mathrm{~s})$. The amplitude of the actual gas temperatures in the bed, $A_{T, \text { cor }}$, is derived by substitution of (B3) and (B4) in (B1). Subsequent values derived for $A_{T, \text { cor }} / A_{\mathrm{T}}$ 
Table A1. Measured values of the mass density, $\rho_{\text {bed }}$, number of particles per unit volume, $N$, and of the void fraction, $\varepsilon$, for the $25 \mathrm{~mm}$ saddles

\begin{tabular}{lcccc}
\hline Bed-type & $\rho_{\text {bed }}\left(\mathrm{kg} / \mathrm{m}^{3}\right)$ & $N\left(\mathrm{~m}^{-3}\right)$ & $\varepsilon$ & $a_{\text {bed }}\left(\mathrm{m}^{-1}\right)$ \\
\hline Open & $681 \pm 12$ & $74.10^{3} \pm 10^{3}$ & $0.72 \pm 0.01$ & $183 \pm 5$ \\
Dense & $764 \pm 13$ & $83.10^{3} \pm 10^{3}$ & $0.68 \pm 0.01$ & $205 \pm 6$ \\
\hline
\end{tabular}

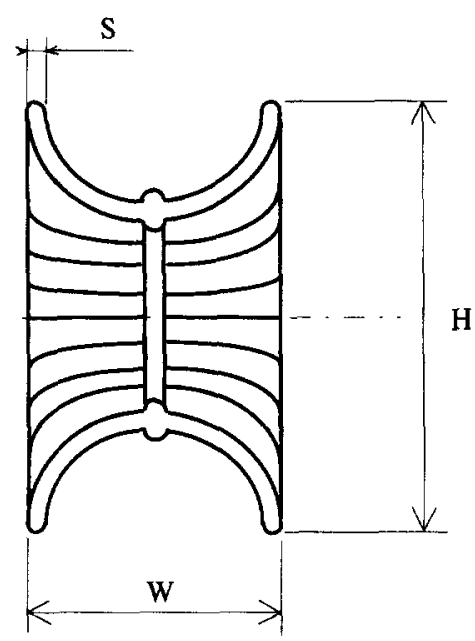

Fig. A1. Schematic of a saddle and characteristic dimensions.

range from 1.7 to 2.3 . Hence, due to the thermal capacity of the thermocouple probe measured temperature amplitudes are about $50 \%$ smaller than the actual gas temperature amplitudes in the packed bed.

\section{NOTATION}

$a_{\text {bed }}$ heat exchanging area per unit bed volume, $\mathrm{m}^{-1}$

$A$ heat exchanging surface area, $\mathrm{m}^{2}$

$A_{f r} \quad$ cross sectional area of packed bed, perpendicular to flow direction, $\mathrm{m}^{2}$

$A_{\mathrm{T}}$ temperature amplitude, $\mathrm{K}$

$c \quad$ heat capacity, $\mathbf{J} /(\mathrm{kg} \mathrm{K})$

$d$ diameter, $\mathrm{m}$

$d_{\text {eq }} \quad$ volume of the particle times 6 divided by the outer surface area of the particle, $m$

$d_{\mathrm{h}} \quad$ mean pore diameter, $\varepsilon \cdot d_{\mathrm{eq}} /(1-\varepsilon), \mathrm{m}$

$h$ convective heat transfer coefficient, $\mathrm{W} /\left(\mathrm{m}^{2} \mathrm{~K}\right)$

$h_{M P} \quad$ axial height of measuring point, see Fig. $3, \mathrm{~m}$

$H \quad$ specific enthalpy, $\mathrm{J} /(\mathrm{kg} \mathrm{K})$

$\dot{m}_{g} \quad$ mass flow rate of gas, $\mathrm{kg} / \mathrm{s}$

$\dot{q}$ heat source, $\mathrm{W}$

$\dot{Q}$ heat flux, $\mathrm{W} / \mathrm{m}^{2}$

Re Reynolds number

$\left\{=\dot{m}_{g} \cdot d_{e q} /\left[(1-\varepsilon) \cdot \rho_{g} \cdot A_{f r} \cdot v_{g}\right]\right\}$

time, $s$

$T$ temperature, $\mathrm{K}$

$v_{s} \quad$ shift velocity, $\mathrm{m} / \mathrm{s}$

$x \quad$ mass fraction, $\mathrm{kg} / \mathrm{kg}$ mixture

$z \quad$ axial coordinate, $\mathrm{m}$
Greek letters

$\Delta H_{0} \quad$ Enthalpy of combustion, $\mathrm{J} / \mathrm{kg}$

$\Delta P \quad$ Pressure drop, $\mathrm{Pa}$

$\Delta T_{\mathrm{ad}} \quad$ Adiabatic temperature drop, see Section 3, $\mathrm{K}$

$\varepsilon \quad$ Void fraction: volume of gas per unit volume of packed bed

$\lambda$ heat conductivity coefficient, $\mathrm{W} /(\mathrm{m} \mathrm{K})$

$v \quad$ kinematic viscosity, $\mathrm{m}^{2} / \mathrm{s}$

$\rho \quad$ mass density, $\mathrm{kg} / \mathrm{m}^{3}$

$\tau \quad$ cycle period (upwards + downwards), $s$

\section{Subscripts}

$\begin{array}{ll}\text { ad } & \text { adiabatic } \\ \text { amb } & \text { to the ambient gas } \\ \text { avg } & \text { average } \\ g & \text { gas phase } \\ \mathrm{HC} & \text { natural gas } \\ \mathrm{H}_{2} \mathrm{O} & \text { water vapor } \\ \text { loss } & \text { lossed } \\ M B & \text { mid-bed zone (plateau) } \\ p & \text { particles }\end{array}$

\section{Superscripts}

out at the outlet (gas)

in at the inlet (gas)

\section{REFERENCES}

Brauer, H. (1971) Grundlagen der Einphasen- und Mehrphasenströmungen. Sauerländer Aarau.

Daszkowski, T. and Eigenberger, G. (1992) Reevaluation of fluid flow, heat transfer and chemical reaction in catalyst filled tubes. Chem. Engng Sci. 47(9-11), 2245-2250.

Eigenberger, G. (1992) Ullmann's Encyclopedia of Industrial Chemistry, B4., VCH, Weinheim.

Eigenberger, G. and Nieken, U. (1988) Catalytic combustion with periodic flow reversal. Chem. Engng Sci. 43(8), 2109-2115.

Gasunie (1988) Physical Properties of Natural Gases., N.V. Nederlandse Gasunie, Groningen, The Netherlands.

Herzfeld, C. M. (1962) Temperature. Its Measurement and Control in Science and Industry. Reinhold, New York.

Kirchner, T. and Eigenberger, G. (1996) Optimization of the cold-start behaviour of automotive catalysts using electrically heated pre-catalyst. Chem. Engng Sci. 51(10), 2409-2418.

Kline, S. J. and McClintock, F. A. (1953) Describing uncertainties in single-sample experiments. Mech. Engng, 75, 3-8.

Levec, J. and Carbonell, R. C. (1985) Longitudinal and lateral thermal dispersion in packed beds. A.I.Ch.E. J. 31(4), 581-602. 
Mackowiak, J. (1991) Fluiddynamik von Kolonnen mit modernen Füllkörpern und Packungen für Gas/ Flüssigkeitssysteme. Verlag Sauerländer AG, Aarau.

Matros, Yu. Sh. (1985) Unsteady Processes in Catalytic Reactors. Elsevier, Amsterdam.

Matros, Yu. Sh. (1989) Studies in Surface Science and Catalysis 43., Elsevier, Amsterdam.

Matros, Yu. Sh. and Noskov, A.S. (1993) Progress in reverse-process application to catalytic incineration problems., Chem. Engng Process. $32,89-98$.

Nieken, U. and Kolios, G. and Eigenberger, G. Control of the ignited steady state in autothermal fixed-bed reactors for catalytic combustion. Chem. Engng Sci. 49(24b), 5507-5518.

Nijdam, J. L. (1995) Behaviour and optimization of packed bed regenerators. PhD thesis, Eindhoven University of Technology.
Nijdam, J. L. and van der Geld, C. W. M. (1997) A comparison of analytical and numerical techniques to model heat transport in reverse flow reactors. Chem. Engng Sci. (submitted).

Perry, R. H. and Green, D. W. and Maloney, J. O. (1984) Perry's Chemical Engineers' Handbook. McGraw-Hill, Singapore.

van de Beld, L., Borman, R. A., Derkx, O. R., van Woezik, B. A. A. and Westerterp, K. R. (1994) Removal of volatile organic compounds from polluted air in a reverse flow reactor: an experimental study. Indust. Engng Chem. Res. 33, 2946-2956.

van de Beld, L. and Westerterp, K. R. (1994) Air purification by catalytic oxidation in a reactor with periodic flow reversal. Chem. Engng Technol. 17, 217-226.

van de Beld, L. and Westerterp, K. R. (1996) Air purification in a reverse flow reactor: model simulations and experiments. A.I.Ch.E. J. 42, 1139-1148. 